\title{
Diabetes insipidus as a predictor of weight gain in craniopharyngeoma patients
}

Tanja Škorić Polovina, Ivana Kraljević, Mirsala Solak, Tina Dušek, Darko Kaštelan

Department of Endocrinology, Clinical Hospital Centre Zagreb, Croatia

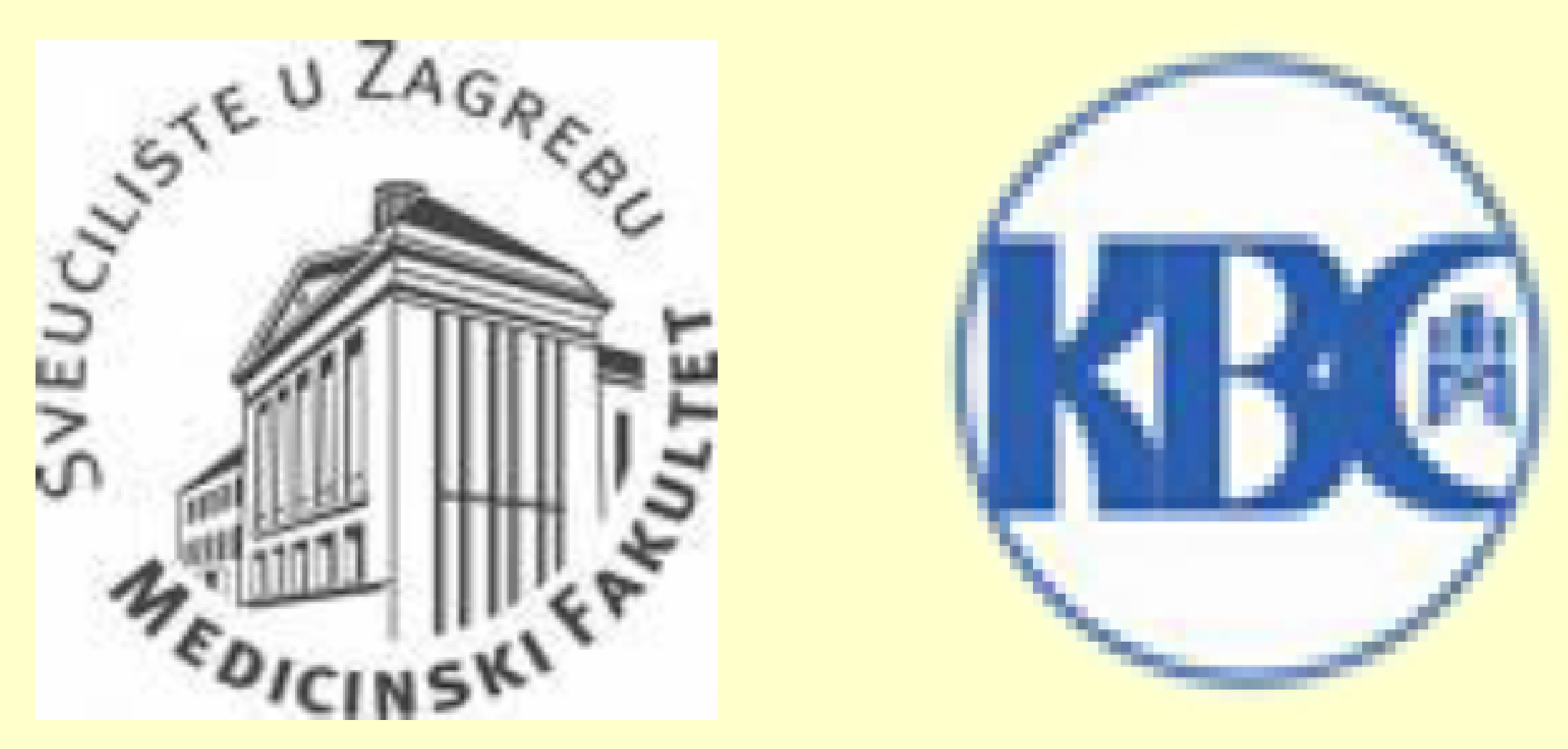

\section{OBJECTIVES}

Craniopharyngeoma patients have reduced quality of life and increased cardiovascular mortality because of severe obesity in about $50 \%$ of patients.

Sellar masses with hypothalamic involvement are associated with lower overall survival and higher body mass index (BMI).

Appearance of diabetes insipidus (DI) indicates hypothalamic damage.

We compared BMI in patients after the treatment of craniopharyngeomas depending on the presence of diabetes insipidus (DI).

\section{METHODS}

We retrospectively analyzed 19 craniopharyngeoma patients (male:female $=12: 7$, mean age 31.2 years, range 9-67) treated at our Clinical Hospital Centre since 2001.

The majority of patients underwent transcranial surgery $(18 / 19)$, $10 / 19$ underwent complete debulking and $9 / 19$ underwent incomplete resection (one or two operations) followed by radiotherapy of residual/recidival tumor.

Body mass index (BMI) was measured before and after the treatment and patients were evaluated for the presence of DI.

\section{RESULTS}

Mean BMI before the treatment was $26,4 \mathrm{~kg} / \mathrm{m}^{2}(17.7-40.8)$. After the treatment mean BMI significantly increased -30.6 $\mathrm{kg} / \mathrm{m}^{2}(23.2-46), \mathrm{p}<0.0001$.

Before the treatment only one patient had DI and after the treatment 13/19 patients had DI. BMI of patients with DI after the treatment was significantly higher in comparison to BMI of patients without DI $\left(31.5 \mathrm{~kg} / \mathrm{m}^{2}(27.1-46)\right.$ in comparison to $\left.27.45 \mathrm{~kg} / \mathrm{m}^{2}(23.2-31.6), \mathrm{p}=0.012\right)$.

\section{CONCLUSIONS}

Craniopharyngeoma patients that developed $\mathrm{DI}$ after the treatment had significantly higher BMI than the patients without DI suggesting that DI represents a clinical surrogate of hypothalamic obesity. 